\title{
Mobile Expert System for Tele-Operating Ultrasound Examination from Any Internet Connected Place in the World
}

\author{
Philippe Arbeille* and Monica Georgescu \\ ${ }^{1}$ UMPS-CERCOM (Unit Med PhysiolSpatiale), Faculte de Medecine, France
}

Submission: March 03, 2017; Published: March 09, 2017

"Corresponding author: Philippe Arbeille, UMPS-CERCOM (Unite Med PhysiolSpatiale), Faculte de Medecine-Université 37032-Tours, France, Email: arbeille@med.univ-tours.fr

\begin{abstract}
Purpose: The objective was to design and validate a mobile expert system for tele operating echographic examination in rural medical centre and extreme environment.

Methods: A tele-operable echograph and probe (Sonoscanner Paris France) was remotely controlled from various distant location (50km to $7000 \mathrm{~km}$ ) using a mobile expert system simply connected to Internet in these places. The mobile Expert system allowed the expert to control the functions (Doppler, 2D, 3D, elastography, etc.) and settings (gain, depth, freeze, record, etc.) of the echograph as well as the orientation of the transducer. The mobile expert system consisted in a portable 11,6 inch computer and a USB connected dummy probe.

Results: 32Tele echographies [abdomen/pelvis ( $n=17$ ),vascular (6), Thyroid, muscle (4), and foetuses (5)] were performed in isolated center in, France, French Guyana, Spain and Romania. During these exams, the expert equipment was activated from various location like, hotels in Europe or in distant countries (USA, Russia, China, France, Italy, Germany, Romania, Spain), train, expert home or holiday residence, and his car. The access to Internet was either by RJ45 wire or WIFI all both connected to a server or from a smart phone connected to Internet by $3 \mathrm{G}$. The Expert completed the tele-echography with in 10 to $20 \mathrm{~min}$.
\end{abstract}

Conclusions: The teleportation of an echograph and probe can be successfully performed from any Internet point (fix or 3G mobile) using the mobile expert equipment. The Tele - operated echgraph $(6 \mathrm{~kg})$ could also be installed in various fixed or moving structures like planes Boat and is presently onboard the International space station for being activated early April 2017.

Keywords: Telemedicine; Tele-echography; Expert centre; Mobile site

\section{Introduction}

Various systems for tele-operating echography on a subject away from the sonographer were developed [1-3]. A non sonographer operator (General practitioner or paramedic) hold a robotic arm or a 3D probe on the patient skin while the expert controls the probe orientation or the 3D scanning.

These systems are controlled from an Expert center located inside a Hospital. The equipment of these Expert centre consists of a PC, both wire connected to an Internet server to collect images/video from the patient site and a dummy probe connected to an electronic module (220 volts powered, wire connected to Internet) from which the expert can send the order to the real probe to change its orientation or to manage the $3 \mathrm{D}$ data collection.

Thus such equipment cannot be easily moved to another place and require that the Expert should operate only from the
Hospital place. In order to make possible the tele-operation from various places like the home of the Sonographer on call, or any other place where the Expert could be we developed a)a portable echograph which settings (gain, depth etc.) and functions (Doppler, 2D, etc.) are tele-operated from away as well as the orientation of the probe transducer, b) a movable (Itinerant)expert system very light $1 \mathrm{~kg}$ connected to Internet through a smartphone (3G) and not requiring any power supply. The hypothesis was that such movable equipment could be sufficient to tele-operate echographies over long distances and from any location Internet connected around the world.

\section{Methods}

\section{Patient site}

The equipment we used in the present application was the Sonoscanner Insert pairs, France portable echograph which can be fully operated via Internet using Team viewer (Goppingen, 
Germany) (Figure 1). All the setting (Gain, depth, Doppler gain...) and function (Pulsed color Doppler, 3D capture, elastography, RF

stowage...) of the Echograph could be controlled and adjusted from an Expert center initially located at the Hospital [4].

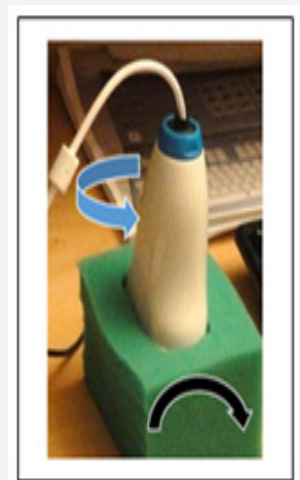

(a)

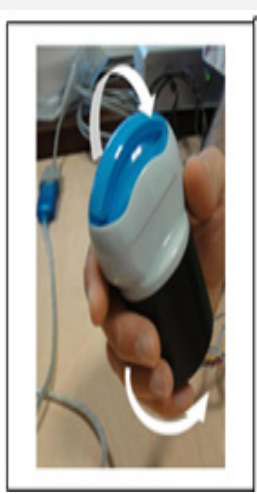

(b)

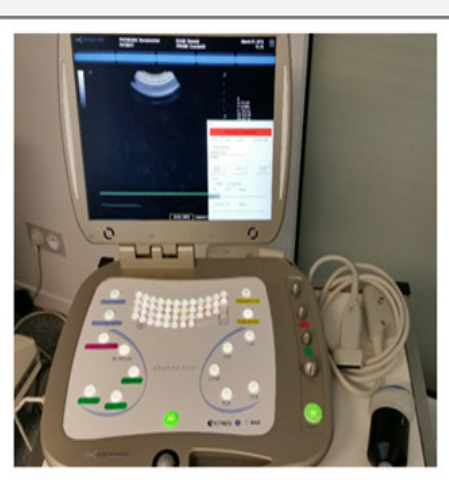

(c)

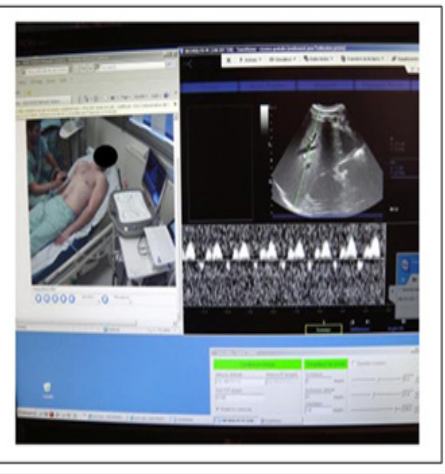

(d)

Figure 1: (a) Dummy probe used by the expert sonographer.

(b) motorized probe on the patient, (arrows = motions of the transducers inside the probes).

(c) Tele- operated Echograph with 2 probes (Sonoscanner-VermonFrance).

(d) Expert PC screen (Left: Ambient \& right: Echography video, bottom: probe tele-operation interface).

\section{Expert site}

The equipment we developed is a movable (itinerant) computer (11.6 inch with a $9 \mathrm{~h}$ battery supply) to which a dummy probe $(150 \mathrm{~g}$ ) is USB connected. The originality of this improved expert center is that it can work simply with a connection to Internet by $3 \mathrm{G}$ through a smart phone. The Teamviewer soft used to import the Image/video coming from the patient site (Ambient and Echo graph screen views) and to send order to control the Echograph, as well as the soft to send order to the probe (Optima log Tours France) to change the orientation of the transducer (Tilting, rotating) are installed on the 11.6 inch PC.
The dummy probe is USB connected to the same PC. The PC is connected by WIFI to the smart phone which provides the access to Internet. Thus the only condition to have the system working is to have a $3 \mathrm{G}$ network (Figure $1 \mathrm{~d} \& 2$ ).

\section{Testing procedure}

The mobile (itinerant) Expert equipment was tested in most of the place where the expert could be when a tele-operated echography is required: in France, in other countries in Europe, America, and Asia, distant by $50 \mathrm{~km}$ to $7000 \mathrm{~km}$ from the patient site (Figure 3).

Result

\section{Patient site location (Figure 2)}
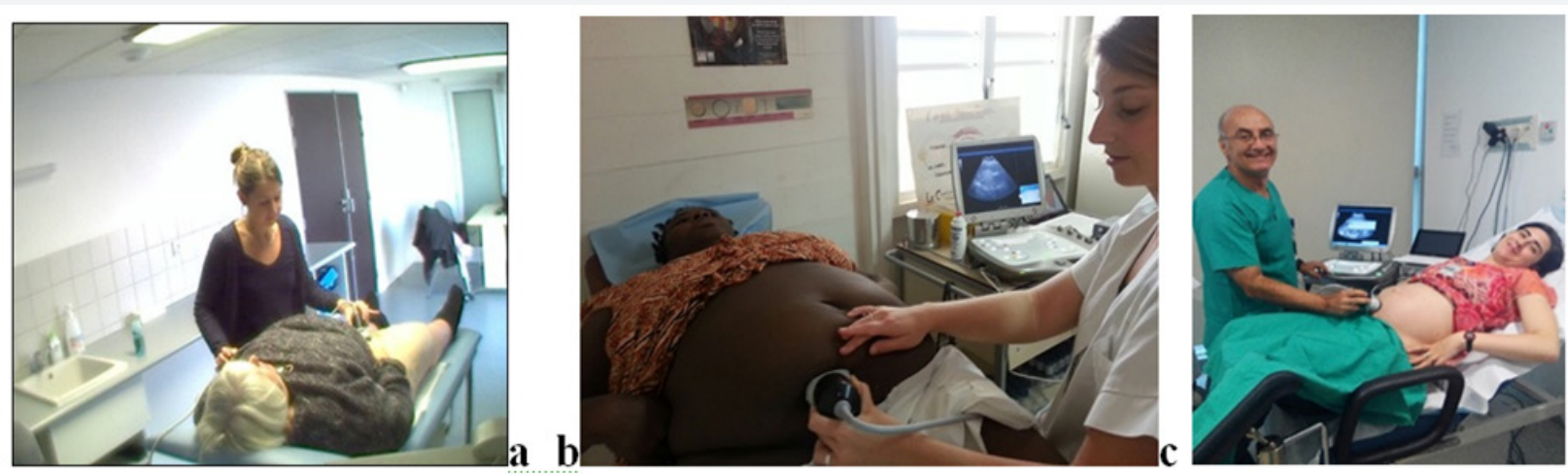

Figure 2: Some of the patient sites:

(a) Health house at Richelieu (5000hab, France),

(b) Apatou dispensary (French Guyana),

(c) Ceuta Medical center (South Spain).

Three patient site were used: in a rural area in France (Richelieu city) at $60 \mathrm{~km}$ from Tours, in the Amazonian forest
(French Guyana: Apatou dispensary), in the south of Spain (Ceuta), Romania. 


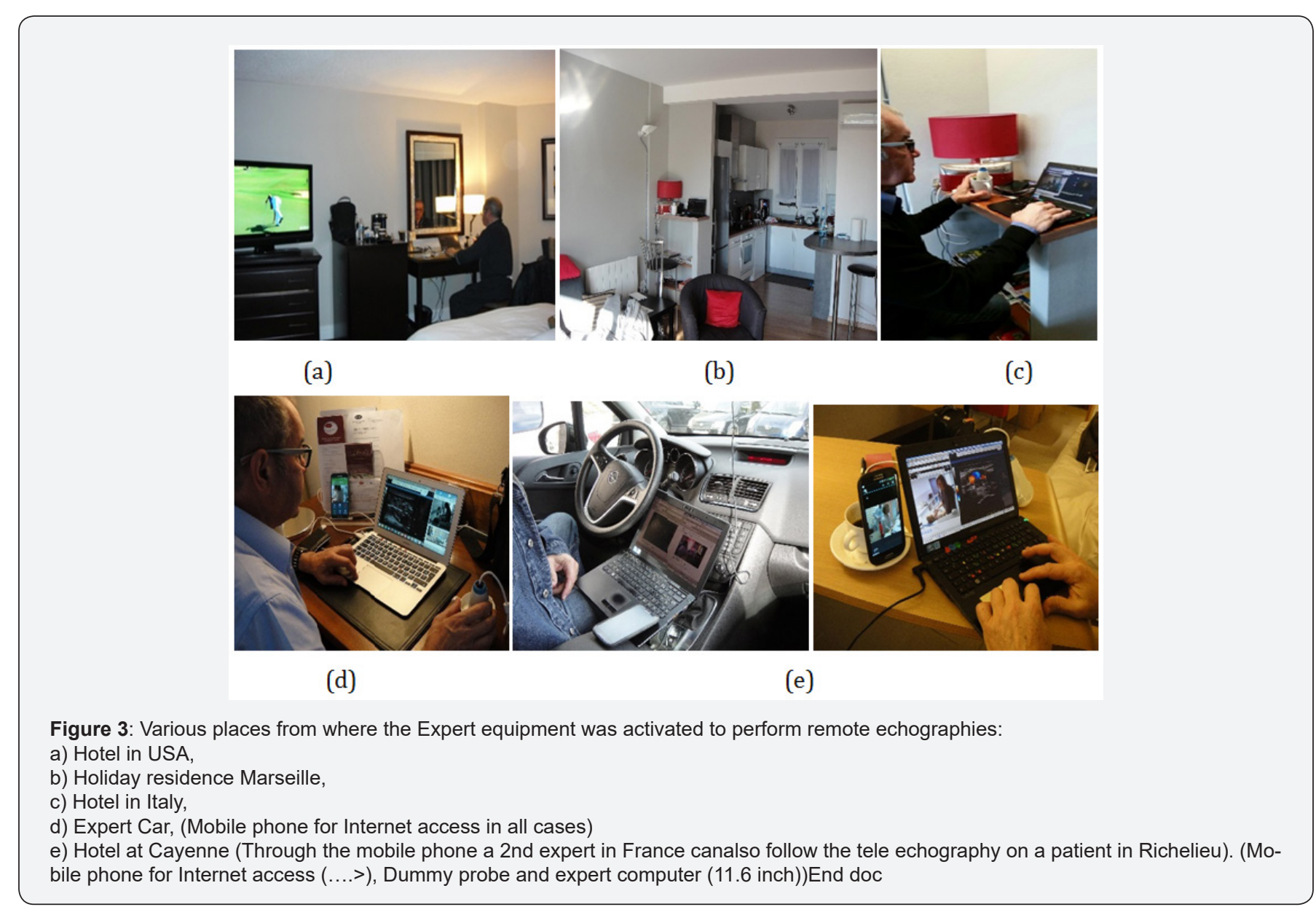

The Expert tele operated echographies on patient located at the patient site of Richelieu from the following areas: Expert home $(60 \mathrm{~km}$ from Richelieu) through his private domestic nonprofessional Internet, Expert Car parked approximately $50 \mathrm{~km}$ away from Richelieu (Smartphone 3G internet), Expert at a Hotel in Trieste (Italy), Koln (Germany), Galate (Romania) (Smartphone 3G internet), Expert in Hotel in Houston and Orlando in the US (WIFI Hotel Internet), Hotel in Moscow Russia (Smartphone 3G Internet). Hotel in Beijing China (Smartphone 3G Internet), Expert in a Train in France (Smartphone 3G Internet).

The expert operated the tele echography on patient located in Ceuta (spain) from his home (private home Internet) and on patient in Guyana both from his home in France and from a hotel in Cayenne (Smartphone 3G Internet\& domestic Internet).

All Tele-operated echographies from the itinerant expert system were appropriately conducted but in some case (approx $15 \%$ ) it was necessary to reset the connection due to fluctuation of the $3 \mathrm{G}$ flow. On the other hand the delay between the time the order was sent to the probe and the time the upgraded image returned to the expert was 1 to $2 \mathrm{~s}$ with ground Internet, except when using the satellite internet the delay could reach $4 \mathrm{~s}$.
During one tele echography performed on a patient located at Richelieu health house in France, from a hotel in Cayenne (French Guyana) a smart phone was used by the expert in Cayenne as an access point to Internet but also to get a visioconference with a second expert located in Tours who followed the tele echography thank's to a connection with the ambient camera and the echo graph of Richelieu. Thus the same mobile expert equipment allows the participation of several experts to the same tele-echography which should be of interest in case of difficult diagnosis (Figure 3e).

\section{Optimized procedure}

Using the mobile expert system the Expert followed the present scenario:

I. Connect to the patient site by visio-conferencing. On the expert PC he write the IP address of the IP camera of the patient site.

II. Connect to the patient Echography Team viewer (Ground Internet by RJ45 or WIFI or 3G or Satellite internet) then depending on the quality of the Internet flow rate he gave priority to the refreshing image speed while searching the good view of the organ. Later on he will set the priority to 
the quality of the image to optimize the view that will serve for the diagnostic.

III. He activates the Optimalog soft for tele-operating the probe transducer.

IV. There are 3 parts on the Expert PC screen: Echo view, ambient (patient) view, Optimalog soft probe interface. During the tele echo the expert can capture image or video he will use for the medical report.

V. The diagnosis is delivered to the physician verbally through the video-conference during the tele-operated examination and with a medical report sent within $30 \mathrm{~min}$. In this report the patient was identified by a number, the real ID was added to the report when received on the PC of the GP at the patient site.

All protocols and procedures were approved by the Hospital Ethics Committee in each patient site. The patient was informed on the tele echography procedure and signed a formal consent.

\section{Discussion}

The tele-operation of an echograph and probe could be successfully activated from any Internet point (fix or 3G mobile) using the mobile expert equipment. The test of the mobile (itinerant) expert equipment looks particularly promising especially when using the $3 \mathrm{G}$ access to Internet. The system has become very flexible as it can be operated from any place on the planet where there is a basic access to Internet. In particular one may notice that using Internet any isolated site will be at 1-2 s with ground Internet 2-4 s with satellite Internet from any expert site.

In case the Expert is moving from an institution or his home to another place or when he is travelling the preparation of the Expert equipment set up can be anticipated while the expert continue its ongoing activity. On any smart phone the Expert can visualize the patient site (IP ambient cameraTinycam soft for Smartphone) and talk to the general practitioner about the patient to come, see when the patient and the GP enter the room... Using its Smartphone he can also see the echograph screen and check the device works well (Team viewer for Smartphone)... while waiting for the patient and GP to be ready. Only a few minutes before the patient and GP are ready the Expert open his PC, select the probe and presets (Carotid, abdomen....), enter patient reference number and activate the dummy probe remote control.

The small sized and light weighted Tele-operated echo graph (40x30x7cm - 6kg) could also be installed and used in case of emergency situation like natural disaster (earthquake) or patient in restricted area (due to microbial or radiation contamination), or onboard moving structure (plane, boat, military vehicle). In each of this application the Expert can be operational anytime from the place where he is. At last the mobile Expert equipment allow the participation of other expert from other expert centre any place in the world as the Internet network allow multiple connection to a single site.

Presently the Tele-operated echo graph is onboard to the International Space Station and will be tele-operated from the ground with the same procedure as for the medical tele echography on earth in early April 2017.

\section{Acknowledgment}

The authors thank Mme. Maryannick Porcher (Sonographer) Mme Roselyne Claveau (Tele-operation assistant) and $\mathrm{Mr}$ Joel Blouin (Engineer) for her active contribution to the teleechography research program.

\section{Grant Support}

The present work was supported by CNES (French Space Agency), R \& T grant: TOURS-2:131512-2014/2015.

Disclosure: No conflicts of interest are declared by the authors.

\section{References}

1. Vieyres P, Poisson G, Courrege F, Merigeaux O, Arbeille P (2003) The TERESA project: from space research to ground tele-echography Ind Rob 30(1): 77- 82.

2. Georgescu M, A Saccomandi, B Baudron, P Arbeille (2015) Remote sonography in routine clinical practice between two isolated medical centers and the University Hospital using a robotic arm (A one year study). Telemedicine \& e-health 22(4): 276-281.

3. Arbeille Ph, B Fornage, A Boucher, J Ruiz, M Georgescu, et al. (2014) Tele sonography : Virtual image processing of remotely acquired abdominal, vascular, and fetal sonograms. J Clin Ultrasound 42(2):6773.

4. ArbeilleP, K Zuj, A Saccomandi, J Ruiz, E Andre, C de la Porte, et al. (2016) (study on 100 patients). Telemed J E Health 22(7): 599-607.

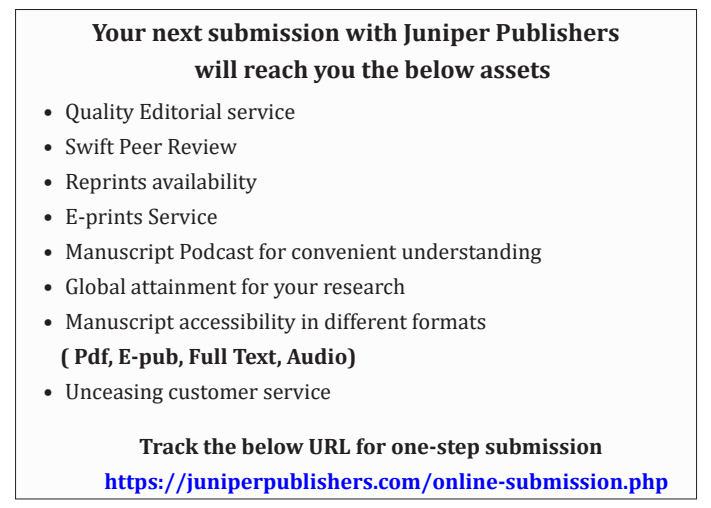

